\title{
DETECTION OF Mmp-8 EXPRESSION IN NANOSILVER-TREATED AND TETRACYCLINE-TREATED PERIODONTITIS INDUCED IN ALBINO RATS
}

\author{
Ghada A. Abdel-Latif* and Wafaa H. El-Hossary*
}

\begin{abstract}
Objective: This study aimed to evaluate the histopathological expression of Mmp-8 in the experimentally-induced periodontitis treated with tetracycline, and nanosilver in albino rats.

Material and Methods: fifty five male albino rats were included in this study. On the first day, 5 rats were euthanized as healthy group for histological characteristics of interdental alveolar bone between the maxillary incisors. Fifty rats were anesthetized; elastic rings were placed around the cervix of the right maxillary incisors for 7 days to induce periodontitis. On the eighth day, the ligatures were removed, five rats were euthanized before any treatment (day zero) and served as positive control group. The remaining 45 rats were randomly assigned to three groups as following: Group I; 15 rats did not receive any treatment. Group II; 15 rats treated locally with tetracycline hydrochloride $(50 \mathrm{mg} / \mathrm{mL})$ daily. Group III; 15 rats treated locally with nanosilver $(12.5 \mu \mathrm{g} / \mathrm{mL})$ daily. Five animals from each group (I, II and III) were euthanized at day 7, 15 and 30 of day zero. The area of the maxillary incisors was decalcified and processed for hematoxylin and eosin stain and immunohistochemical stain for Mmp-8.
\end{abstract}

Results: Local application of nanosilver in experimentally-induced periodontitis in rats exhibited tendency for bone formation from day 7 with externalization of the inflammation compared to local application of tetracycline. The tetracycline treatment demonstrated tendency for localization of inflammation detected as abscess formation. The tendency for new bone formation was detected after 15 days of treatment. Mmp-8 expression was strongly expressed after the induction of periodontitis. In nanosilver treated group, Mmp- 8 started to fade within the connective tissue from day 15 and was detected only on the surface epithelium. In tetracycline group, Mmp- 8 was detected at day 15 surrounding the abscesses then it completely disappeared at day 30 .

Conclusion: Mmp-8 is intensely expressed in inflamed periodontal tissue. This expression fades earlier with the nanosilver treatment compared to the tetracycline treatment. The noninflamed periodontal tissues did not express Mmp-8.

KEYWORDS: nanosilver, tetracycline, rats, matrix metalloproteinase-8, experimentallyinduced periodontitis, immunohistochemistry.

* Department of Oral Pathology, Faculty of Dentistry, Suez Canal University, Ismalia, Egypt 


\section{INTRODUCTION}

Periodontitis is a chronic inflammatory disease that affects the periodontal tissues and results in teeth loss ${ }^{(1)}$. Multiple etiological factors cause its initiation and progression ${ }^{(2)}$. Early detection and prevention of the periodontal disease is highly effective and has considerable health-care benefit regarding time and cost ${ }^{(3)}$.

Systemic therapy of periodontal disease by antimicrobial agents has been used for many years in combination with the local measures as scaling and root planning. The systemic antibiotics released in saliva and gingival fluid enhance treatment of the periodontal disease via different ways. It helps killing the bacteria residing in the periodontal tissues where it cannot be removed by local measures and hence allows for the non-surgical treatment of periodontal disease ${ }^{(4)}$. The presence of periodontal tissues free of causative bacteria allows re-attachment and bone regeneration ${ }^{(5)}$.

Tetracyclines, penicillin, erythromycin, spiramycin, amoxycillin, chlavulanic acid and clindamycin, were used to treat periodontal disease at certain concentrations ${ }^{(6)}$. The most commonly used and potent antibiotic against periodontal disease is tetracyclines in a dose of $250 \mathrm{mg}$ four times per day for 1 or 2 weeks. Minocycline administration has also been used as an adjunctive treatment ${ }^{(7)}$. Due to the potent effect of tetracycline, it was used for several years as systemic antibiotic therapy for treating periodontal diseases ${ }^{(8)}$.

New modality in medicine has been developed like the use of nanotechnology in treatment of many diseases due to the efficient delivery of nanoparticles to targeted tissue cells. Silver nanoparticles are one of the most famous nanoparticles used in medicine. They can accelerate wound healing and act as strong anti-inflammatory agent ${ }^{(9,10)}$. Silver nanoparticles have a high specific surface area and a high fraction of surface atoms that lead to high antimicrobial activity compared to bulk silver metal ${ }^{(11)}$.
The use of nanosilver particles as wound dressing for surgically-treated periodontal diseases in a white adolescent female rabbit revealed high improvement of wound healing ${ }^{(11)}$. In addition, irrigation with nanosilver solution was found effective in treating periodontitis induced in albino rats ${ }^{(12)}$.

The wound healing process and inflammatory disease like periodontitis require remodelling of the extracellular matrix which is a complex process that needs a variety of proteinases such as matrix metalloproteinases (MMPs) ${ }^{(13,14)}$.

The matrix metalloproteinases are large family of more than 26 members that are highly sensitive to regulation processes that include transcription, proenzymes secretion and activation. Later on, the activation is controlled by a set of specific inhibitors called tissue inhibitor of matrix metalloproteinases (TIMPs) $^{(15)}$.

Matrix metalloproteinases are classified into major five groups: collagenases (MMP-1, -8 and -13), gelatinases (MMP-2 and -9), stromelysins (MMP-3,-10and-11), membrane-type matrix metalloproteinases (MMP-14, -15, -16 and -17), and others ${ }^{(16,17)}$.

A collagenase enzyme was firstly described in 1968. It was isolated from human polymorphonuclear leukocytes (PMNLs) ${ }^{(18,19)}$ thus it was given the name PMNL- collagenase or neutrophil collagenase. It is also known as matrix metalloproteinase- 8 $(\mathrm{MMP}-8)^{(20)}$.

Matrix metalloproteinase-8 (MMP-8, collagenase-2) is a proteolytic enzyme secreted mainly by neutrophil leukocytes as a latent pro-enzyme that can be activated by inflammatory irritants secreted by either host cells or bacteria ${ }^{(21,22)}$.

MMP-8 is the major collagenase found in saliva, inflamed human gingiva and gingival crevicular fluid (GCF) ${ }^{(23,24)}$. It is suggested that MMP-8 can serve as a marker of periodontal tissue destruction, due to the raised levels of MMP-8 in gingival 
crevicular fluid of periodontitis patients, especially the chronic cases ${ }^{(25-27)}$. Therefore, this study aimed to detect the changes in Mmp-8 expression in the interdental tissues of rats following induction of periodontitis and treatment with either tetracycline or nanosilver.

\section{MATERIAL AND METHODS}

Fifty five male albino rats with average weight of $200 \mathrm{~g}$ were used for this study. At the beginning, five healthy rats (healthy control group) were euthanized for identification of the normal histological characteristics of interdental alveolar bone between the maxillary incisors.

Periodontitis was induced in the other 50 rats by placing elastic rings around the cervix of the right maxillary incisors for 7 days ${ }^{(12,28,29)}$. The rats were anaesthetized with intramuscular Xylaject $(5 \mathrm{ml} / \mathrm{kg}$ body weight) injection. On the $8^{\text {th }}$ day the rings were removed without anaesthesia and five animals were euthanized at this point as a positive control group.

The remaining 45 animals were randomly assigned to three groups (15 rats each) according to the treatment strategy as follows;

Group I (GI, no treatment group); did not receive any treatment in order to represent the selfregression of periodontitis after ligature removal over the 30 days period of the study. Group II (Tetracycline-treated group); rats treated with $1 \mathrm{ml}$ tetracycline hydrochloride $(50 \mathrm{mg} / \mathrm{ml})$ daily, deposited into the induced pocket slowly (30s), using a syringe $(1 \mathrm{ml})$ with an insulin needle without bevel. Group III (Nanosilver-treated group); rats treated with nanosilver $(12.5 \mu \mathrm{g} / \mathrm{ml}$, kindly supplied by Dr. Mona Bakr, Nano-Tech Company, Dream Land, Wahaat Road, 6th October, Egypt) daily, deposited into the induced pocket slowly as in GII. Five animals from each group (I, II and III) were euthanized at days 7,15 and 30 after ligature removal with a lethal dose of thiopental $(150 \mathrm{mg} / \mathrm{kg}$ body weight). The maxillae were dissected out and stored in $10 \%$ neutral formalin ${ }^{(12)}$.

The specimens were demineralized in $10 \%$ EDITA solution (containing 5\% sodium sulphide), dehydrated in alcohol, cleared in xylene and embedded in paraffin wax blocks. Longitudinal mesiodistal sections of $5 \mu \mathrm{m}$ thickness, including interdental alveolar bone between maxillary incisors were stained for hematoxylin-eosin ${ }^{(30)}$.

\section{Immunohistochemistry:}

Tissue sections were deparaffinized in xylene, rehydrated in graded alcohols. Antigen retrieval was done in microwave for $3 \mathrm{~min}$ at $80^{\circ} \mathrm{C}$ followed by 10 min at $20^{\circ} \mathrm{C}$. Mmp- 8 staining was carried out using Rabbit monoclonal antibody to Mmp-8 (ab81286 Abcam Inc, Cambridge,USA) diluted 1:100. Staining detection was carried out using Novolink polymer detection system (RE7140-CE Novolink Polymer DS) following the manufacturer's instructions. Stained tissue sections were photographed using the Olympus BX50 microscope (Olympus America, Center Valley, PA) with an attached Olympus E330ADU1X Camera (Japan).

\section{RESULTS}

Calculus accumulated on the central incisors after the application of elastic ring ligature for 7 days. Gingivitis was detected clinically as oedema, redness, bleeding on touch and recession.

\section{Histopathological results:}

Examination of stained tissue sections of positive control group revealed periodontitis as severe inflammation and alveolar bone loss compared to the healthy group with normal periodontal tissues (fig.1 A and B).

Examination of GI (no treatment) H\&E sections revealed severe inflammation in the periodontal tissues for 15 days. While partial healing was detected by day 30 (figure 2-A, D, G). 


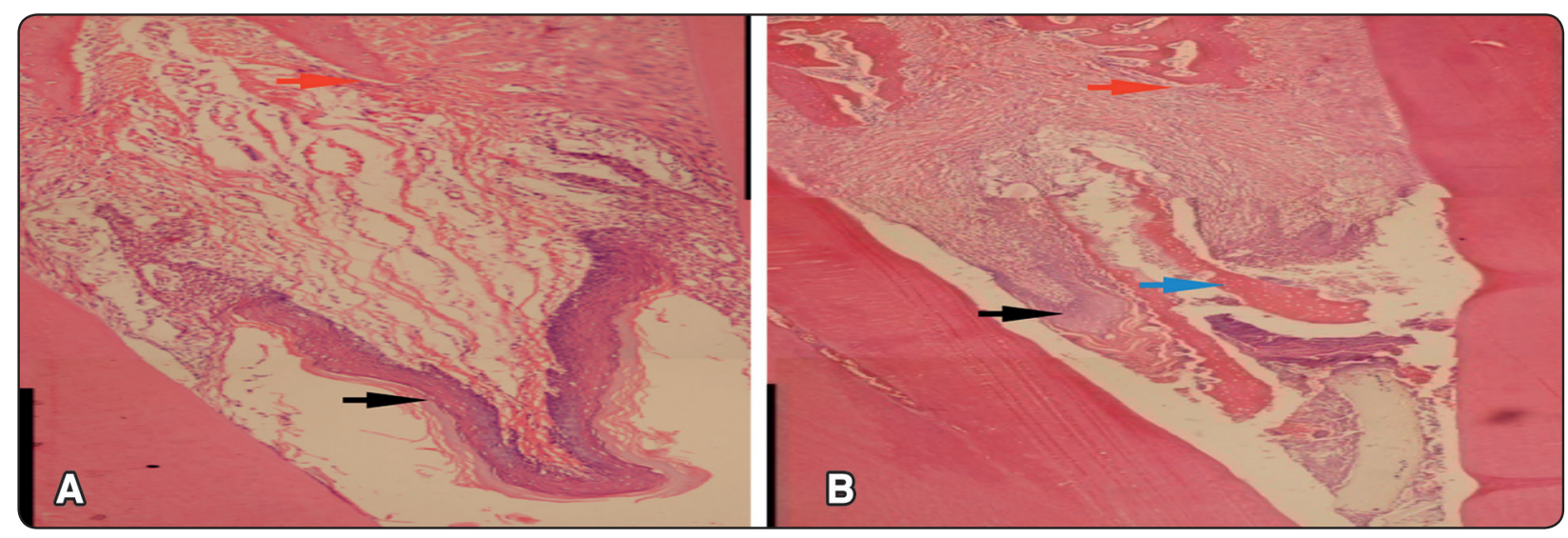

Fig. (1): Photomicrograph of the interdental area before and after induction of periodontitis. (A) Healthy group, showing normal pointed alveolar bone crest with the PDL fibers connecting bone and dentin (red arrow) and the intact epithelial covering (black arrow). (B) Positive control group showing severely inflamed interdental area with resorption of alveolar bone crest (red arrow), bone sequestra (blue arrow) and disrupted epithelial covering indicative of periodontitis. (H\&E x10)

For the tetracycline-treated group (GII), there was a tendency for localization of the inflammation and abscess formation at day 15 . In addition, healing process in the form of new bone formation and organization of the periodontal fibres was detected. By the end of the month, healthy periodontal tissues were regained (figure 2-B,E,H).
Nanosilver treatment (GIII) tended to externalize the inflammation with bony sequestrum was extruded outside the tissues. The tendency for new bone formation and organization of the periodontal fibres were detected at day 7 . The healing process and re-epithelialisation continued over the second week of treatment. The normal healthy periodontal tissues were detected by day 30 (figure 2-C, F, I).

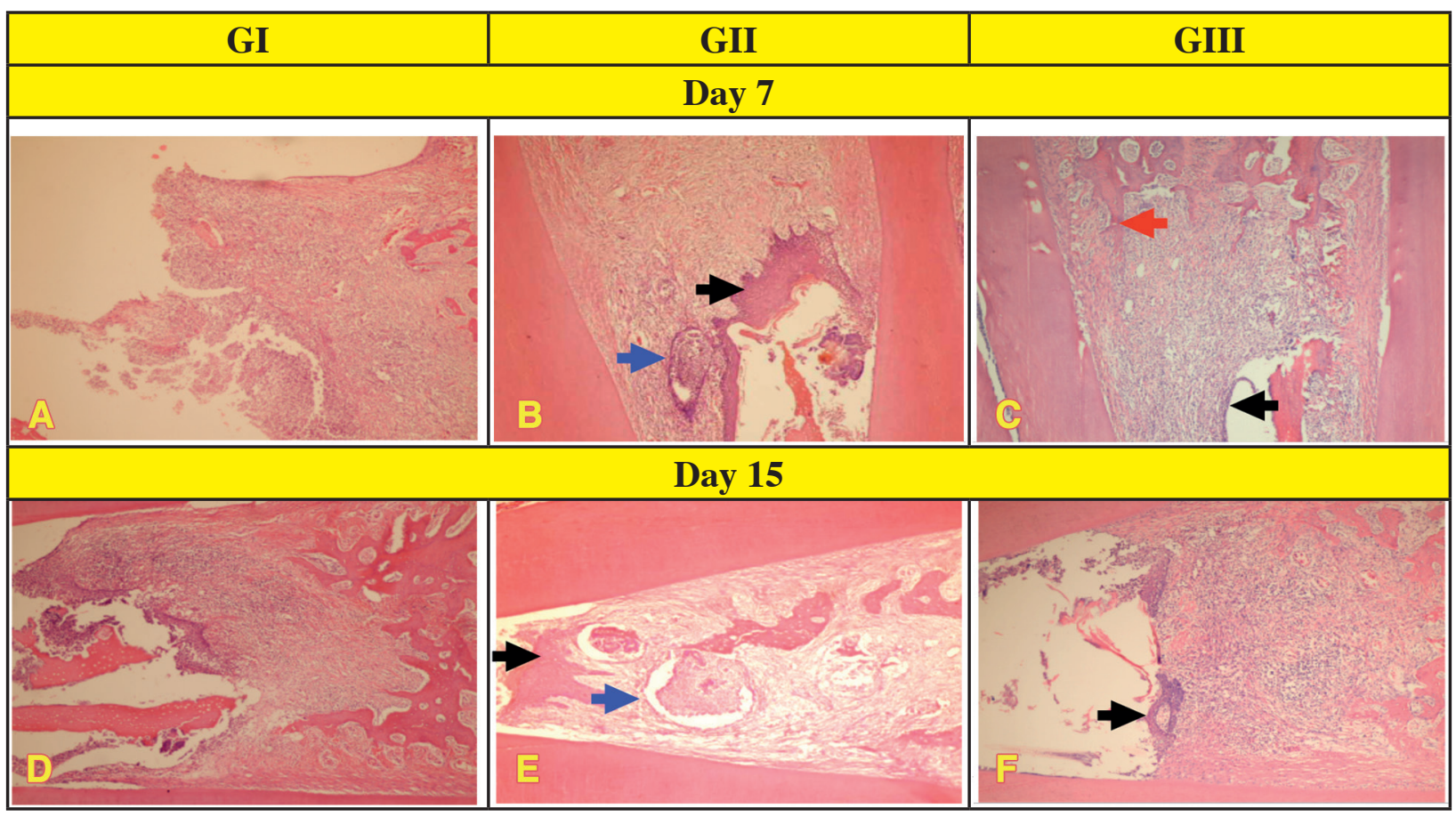




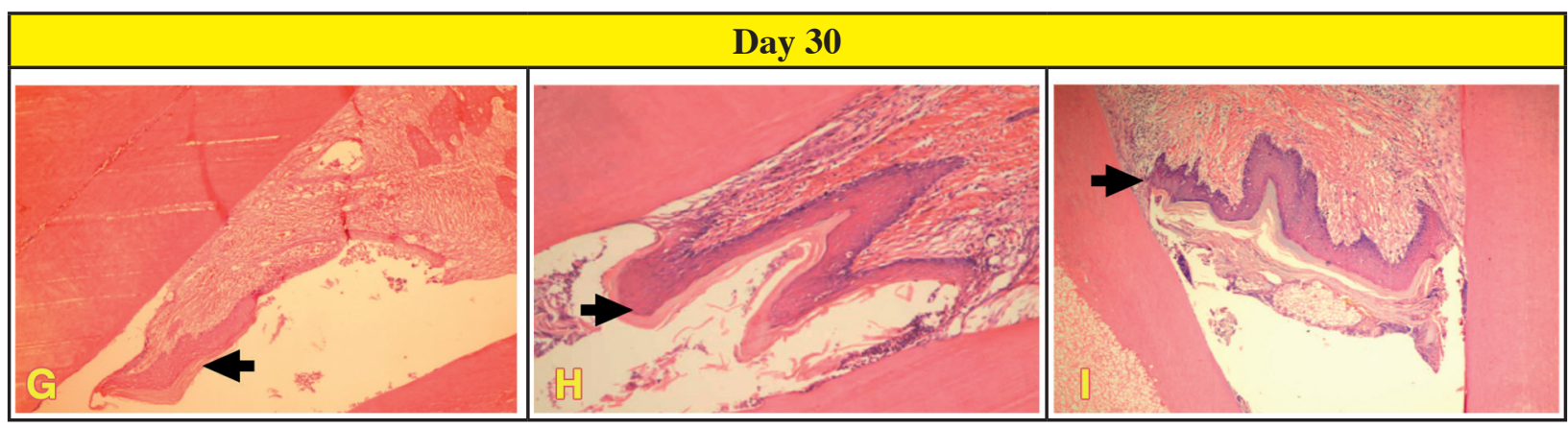

Fig. (2): Photomicrographs of the interdental area showing tissue response to treatment at different time points. GI (no treatment); A, D, showing severe inflammation. G, healing started with incomplete epithelial covering (black arrow). GII (tetracycline); abscess formation was evident in $\mathrm{B}$ and $\mathrm{E}$ (blue arrow) while in $\mathrm{H}$ tissues were back to normal with epithelial covering (black arrow). GIII (nanosilver); C, bone formation and organization of PDL fibers (red arrow) were detected after 7 days of treatment. The healing continued in $\mathrm{F}$ and complete epithelial coverage was detected in I (black arrow). (All micrographs are $\mathrm{H} \& \mathrm{E}$ x10 except $\mathrm{H}$ x20).

\section{Immunohistochemical results:}

\section{Mmp-8 expression}

The healthy periodontal tissues were completely negative for Mmp-8 while the glandular tissues were positively stained (figure 3-A, -B). The positive control group demonstrated strong Mmp8 expression in the interdental area where the inflammatory cells accumulated (figure 3-C).

GI showed strong Mmp-8 expression at 7 and 15 days. By day 30, Mmp-8 expression was limited to the expelled inflammatory cells.

GII demonstrated strong Mmp-8 expression at day 7. At day 15, the expression was milder around the abscess formation and by day 30 it was detected supra-epithelial.

In GIII group, Mmp-8 was strongly detected in the connective tissue and surrounding the bony sequestra at day 7 . By day 15 , the expression was limited to the supra-epithelial area. By day 30 , the supra epithelial expression faded.

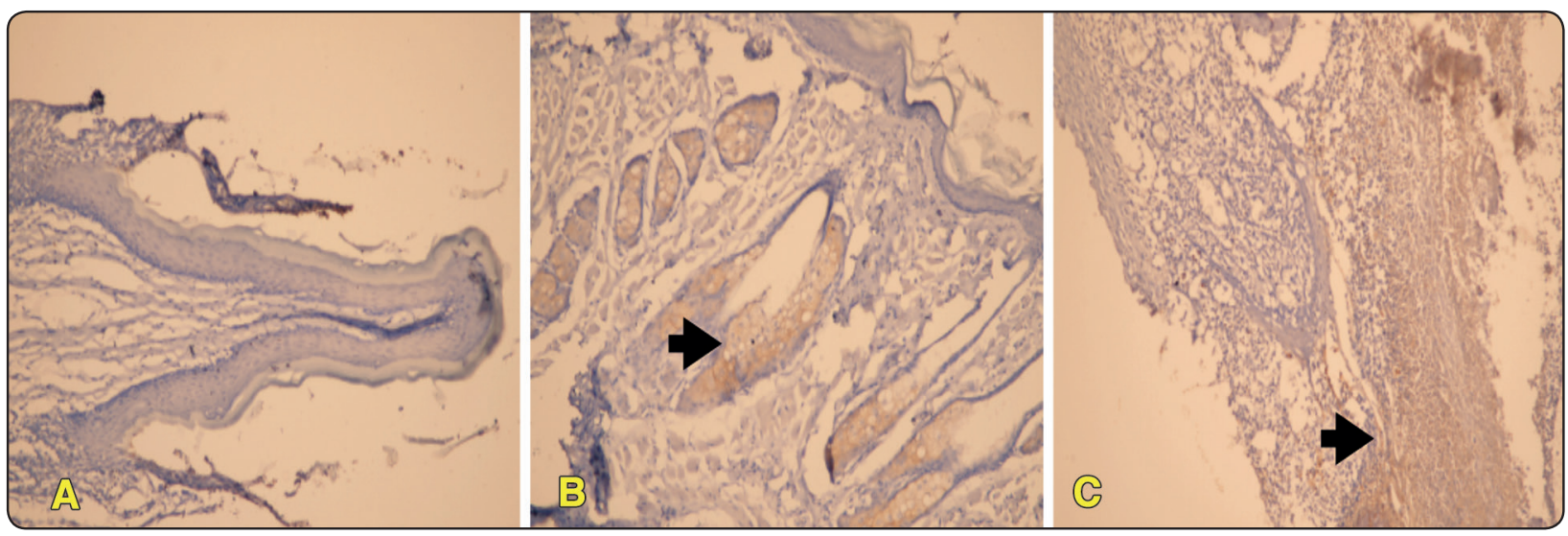

Fig. (3): Mmp-8 expression in the interdental tissues before and after induction of periodontitis. A, the interdental tissues were Mmp-8 negative in the healthy control group while the glandular tissues were positively stained (black arrow) as shown in B. C, strong Mmp-8 expression in the interdental tissues of the positive control group (black arrow). (Mmp-8 IHC x20). 


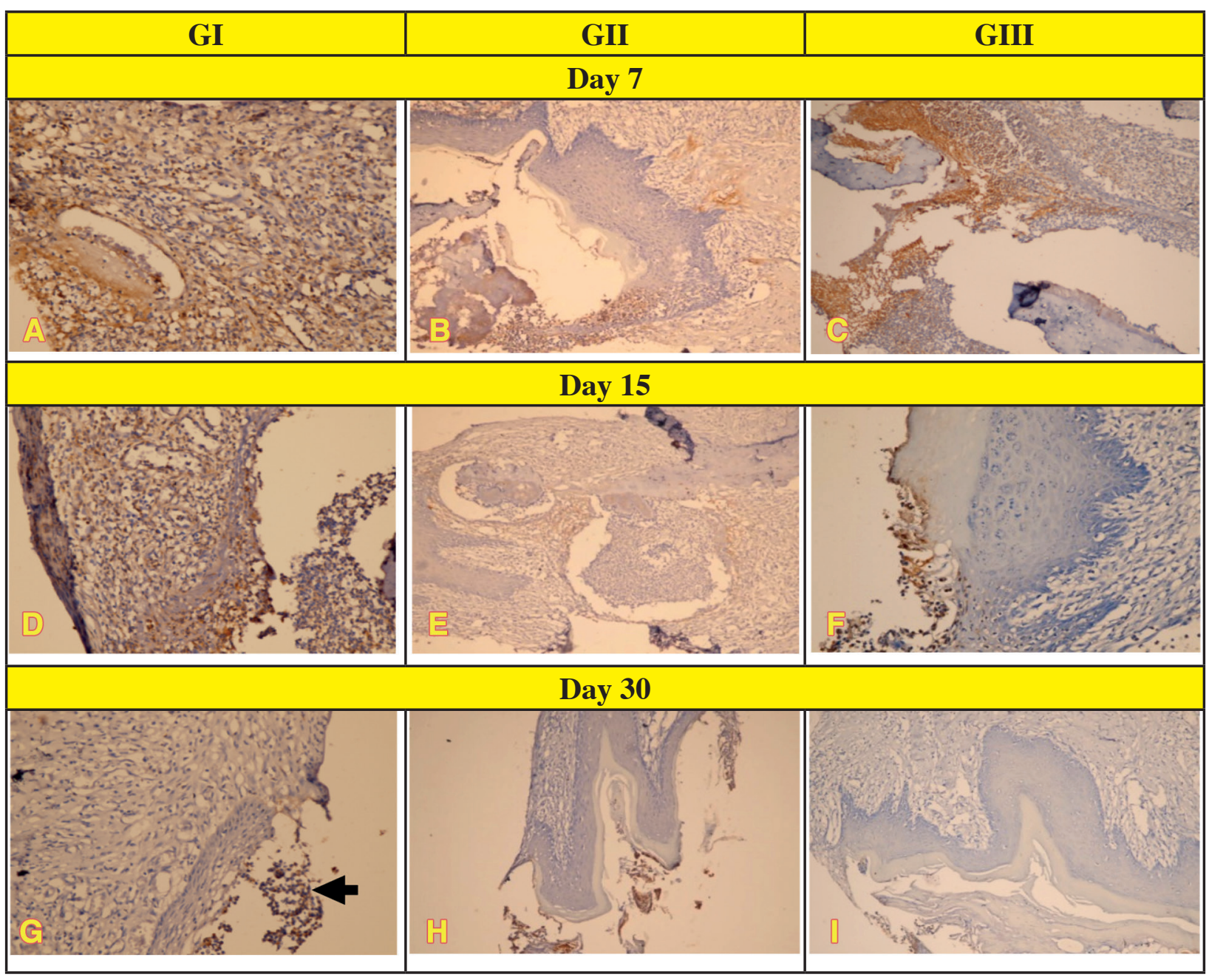

Fig. (4): Photomicrographs of Mmp-8 expression in the interdental area following treatment at different time points. GI (no treatment); A, D, showing strong Mmp-8 expression (days 7\&15). G (day 30), Mmp-8 expression was detected only supraepithelial (black arrow). GII (tetracycline); Mmp8 expression was strong in B (day7) then its intensity faded in E (day 15) till it was detected only supra-epithelial in $\mathrm{H}$ (day 30). GIII (nanosilver); Mmp-8 was strongly detected in C (day 7) while it was supra-epithelial only in F (day 15) then it faded in I (day 30). (Mmp-8 IHC x40 A,D,G \&F , x20 B,C,E,H \& I)

\section{DISCUSSION}

The protocol used was successful in the induction of periodontitis in albino rats. It avoided the hormonal effect on bone resorption through the selection of male rats rather than the females. The application of the elastic rings on the incisor cervix acted as a retentive factor for the microbial plaque which in turn induced inflammation in the gingival and periodontal tissues. Histologically, the tissues were severely inflamed with marked bone resorption and interruption of the epithelial coverage of the interdental papilla. The use of this protocol for the induction of periodontitis was reported by previous researchers ${ }^{(12,28,31)}$.

The induced periodontitis was treated through topical application of the antimicrobial agents based on Goodson's findings in 1994. He reported that drug delivery through local routes has the benefit of reaching higher drug concentration at the target site with the avoidance of systemic hazards ${ }^{(6)}$.

Using nanosilver as an alternate for antibiotics is in accordance with the ongoing research on its use 
as antimicrobial drug in various fields ${ }^{(32,33)}$. In the used model, it resulted in earlier improvement of the induced periodontitis compared to tetracycline treatment. This finding was in agreement with Hassan et al results in 2014, who described earlier decrease in inflammatory cell count and increased bone mineral density with the use of nanosilver compared to tetracyclines ${ }^{(12)}$.

The improved periodontitis could be attributed to the bactericidal properties of silver nanoparticles which are explained by various mechanisms. Silver particles at the nanoscale have extremely large surface area providing better attachment to the bacterial cell membrane and easier penetration to its inside ${ }^{(34)}$. Bacterial death could be achieved through attacking the respiratory chain in the microbial mitochondria by the silver nanoparticles ${ }^{(35)}$. In addition, disruption of the microbial cell membrane takes place through the interaction between silver nanoparticles and the sulphur containing proteins on the cell membrane ${ }^{(36)}$. Moreover, silver ions released inside the microbial cell results in free radicals' formation and induction of oxidative stress resulting in bacterial death ${ }^{(37)}$.

On the other hand, the anti-inflammatory effect of silver nanoparticles was attributed to the induced apoptosis of inflammatory cells and decrease expression of some inflammatory cytokines ${ }^{(38)}$. In addition, matrix metalloproteinases demonstrated decreased expression upon treatment of ulcerative conditions with nanosilver ${ }^{(39)}$.

It is well established that MMPs are key proteolytic enzymes for periodontal tissue destruction ${ }^{(17)}$, and it seems that MMP-8 (collagenase-2) plays a central role in the turnover and degradation of periodontal tissues ${ }^{(16)}$. Golub et al. stated that MMP- 8 accounts for $80 \%$ of the total collagenase protein found in gingival crevicular fluid of chronic periodontitis patients ${ }^{(40)}$. However, it should be emphasized that Mmp-8, especially at physiologic levels, can also exert anti-inflammatory effects by processing some anti-inflammatory cytokines and chemokines ${ }^{(41,42)}$.
In the present study, the expression of Mmp- 8 was strong in the interdental tissues of the positive control group which were heavily infiltrated with inflammatory cells. Whereas the interdental tissues in the healthy control group were completely negative for Mmp-8. This finding could be on line with the high expression of MMP-8 in the gingival crevicular fluid of patients with periodontitis compared to healthy controls ${ }^{(43-45)}$. In addition, other authors detected high MMP-8 levels in the saliva of periodontitis patients compared to healthy individuals ${ }^{(46,47)}$.

The level of MMP-8 in the crevicular fluid and/or saliva was used by various researchers as a biological marker for monitoring the improvement of periodontitis in response to various treatment protocols ${ }^{(44,45)}$. They reported decrease in MMP8 levels with improvement of periodontitis in response to treatment. Their findings support the present finding of decreased Mmp-8 levels in the interdental tissues of the nanosilver treated group.

The earlier disappearance of Mmp-8 (day 15) from the tissues treated with nanosilver compared to tetracycline-treated tissues (day30) is most probably related to the significant decrease in the inflammatory cells in the area as reported by Hassan et al $2014^{(12)}$.

The rat glandular tissues showed persistent Mmp-8 positivity in all groups. This finding could not be explained through the literature therefore further studies are required. It could be proposed that the presence of Mmp- 8 as a regular constituent of the rat salivary secretion aids in softening the hard diet it consumes as a mean of protection of the mucosa lining the oral cavity and the digestive tract.

More researches should be carried out to study the biological advantages of using nanosilver as coat for implants and monitoring its biological and pathological effect using MMP-8 expression. 


\section{REFERENCE}

1. Loe H., Anerud A., Boysen H. and Morrison E. Natural history of periodontal disease in man. Rapid, moderate and no loss of attachment in sri lankan laborers 14 to 46 years of age. J Clin Periodontol. 1986 May;13(5):431-45.

2. Listgarten M. A. Pathogenesis of periodontitis. J Clin Periodontol. 1986 May;13(5):418-30.

3. Slots J. Periodontology: Past, present, perspectives. Periodontol 2000. 2013 Jun;62(1):7-19.

4. Atilla G., Balcan M., Bicakci N. and Kazandi A. The effect of non-surgical periodontal and adjunctive minocyclinehcl treatments on the activity of salivary proteases. J Periodontol. 1996 Jan;67(1):1-6.

5. Saito A., Hosaka Y., Nakagawa T., Seida K., Yamada S. and Okuda K. Locally delivered minocycline and guided tissue regeneration to treat post-juvenile periodontitis. A case report. J Periodontol. 1994 Sep;65(9):835-9.

6. Goodson J. M. Antimicrobial strategies for treatment of periodontal diseases. Periodontol 2000. 1994 Jun;5:142-68.

7. Walker C. B., Gordon J. M., Magnusson I. and Clark W. B. A role for antibiotics in the treatment of refractory periodontitis. J Periodontol. 1993 Aug;64(8 Suppl):772-81.

8. van Winkelhoff A. J., Rams T. E. and Slots J. Systemic antibiotic therapy in periodontics. Periodontol 2000. 1996 Feb;10:45-78.

9. Chaloupka K., Malam Y. and Seifalian A. M. Nanosilver as a new generation of nanoproduct in biomedical applications. Trends Biotechnol. 2010 Nov; 28(11):580-8.

10. Sharma V.K., Yngard R. A. and Lin Y. Silver nanoparticles: Green synthesis and their antimicrobial activities. Adv Colloid Interface Sci. 2009 Jan 30;145(1-2):83-96.

11. Habiboallah G., Mahdi Z., Majid Z., Nasroallah S., Taghavi A. M., Forouzanfar A. and Arjmand N. Enhancement of gingival wound healing by local application of silver nanoparticles periodontal dressing following surgery: A histological assessment in animal model. Modern Research in Inflammation. 2014;3:128-38.

12. Hassan M. M. A., El-Hossary W. H. and Al- Ajabri A. Q. Local effect of nanosilver on treatment of experimentallyinduced periodontitis in albino rats. . Egypt Dent J. 2014;60(2):2445-54.

13. Stetler-Stevenson W. G. Matrix metalloproteinases in angiogenesis: A moving target for therapeutic intervention. J Clin Invest. 1999 May;103(9):1237-41 .
14. Soo C., Shaw W. W., Zhang X., Longaker M. T., Howard E. W. and Ting K. Differential expression of matrix metalloproteinases and their tissue-derived inhibitors in cutaneous wound repair. Plast Reconstr Surg. 2000 Feb;105(2):638-47.

15. Unemori E. N., Bouhana K. S. and Werb Z. Vectorial secretion of extracellular matrix proteins, matrix-degrading proteinases, and tissue inhibitor of metalloproteinases by endothelial cells. J Biol Chem. 1990 Jan 5;265(1):445-51.

16. Sorsa T., Tjaderhane L. and Salo T. Matrix metalloproteinases (mmps) in oral diseases. Oral Dis. 2004 Nov;10(6):311-8.

17. Sorsa T., Tjaderhane L., Konttinen Y. T., Lauhio A., Salo T., Lee H. M., Golub L. M., Brown D. L. and Mantyla P. Matrix metalloproteinases: Contribution to pathogenesis, diagnosis and treatment of periodontal inflammation. Ann Med. 2006;38(5):306-21.

18. Lazarus G. S., Brown R. S., Daniels J. R. and Fullmer H. M. Human granulocyte collagenase. Science. 1968 Mar 29;159(3822):1483-5.

19. Lazarus G. S., Daniels J. R., Lian J. and Burleigh M. C. Role of granulocyte collagenase in collagen degradation. Am J Pathol. 1972 Sep;68(3):565-78.

20. Nagase H., Barrett A. J. and Woessner J.F., Jr. Nomenclature and glossary of the matrix metalloproteinases. Matrix Suppl. 1992;1:421-4.

21. Ryan M. E., Ramamurthy S. and Golub L. M. Matrix metalloproteinases and their inhibition in periodontal treatment. Curr Opin Periodontol. 1996;3:85-96.

22. Sorsa T., Ingman T., Suomalainen K., Haapasalo M., Konttinen Y. T., Lindy O., Saari H. and Uitto V. J. Identification of proteases from periodontopathogenic bacteria as activators of latent human neutrophil and fibroblast-type interstitial collagenases. Infect Immun. 1992 Nov;60(11):4491-5.

23. McCulloch C. A. Collagenolytic enzymes in gingival crevicular fluid as diagnostic indicators of periodontitis. Ann N Y Acad Sci. 1994 Sep 6;732:152-64.

24. Sorsa T., Uitto V. J., Suomalainen K., Vauhkonen M. and Lindy S. Comparison of interstitial collagenases from human gingiva, sulcular fluid and polymorphonuclear leukocytes. J Periodontal Res. 1988 Nov;23(6):386-93.

25. Mantyla P., Stenman M., Kinane D. F., Tikanoja S., Luoto H., Salo T. and Sorsa T. Gingival crevicular fluid 
collagenase-2 (mmp-8) test stick for chair-side monitoring of periodontitis. J Periodontal Res. 2003 Aug;38(4):436-9.

26. Sorsa T., Mantyla P., Ronka H., Kallio P., Kallis G. B., Lundqvist C., Kinane D. F., Salo T., Golub L. M., Teronen O. and Tikanoja S. Scientific basis of a matrix metalloproteinase- 8 specific chair-side test for monitoring periodontal and peri-implant health and disease. Ann N Y Acad Sci. 1999 Jun 30;878:130-40.

27. Kinane D. F., Darby I. B., Said S., Luoto H., Sorsa T., Tikanoja S. and Mantyla P. Changes in gingival crevicular fluid matrix metalloproteinase- 8 levels during periodontal treatment and maintenance. J Periodontal Res. 2003 Aug;38(4):400-4.

28. Shoji K., Horiuchi H. and Shinoda H. Inhibitory effects of a bisphosphonate (risedronate) on experimental periodontitis in rats. J Periodontal Res. 1995 Jul;30(4):277-84.

29. Refei A. M., Fetaih H. A., Goda O. M. and Morsy S. M. Preventive effect of alendronant and doxycycline on alveolar bone resorption in experimental periodontitis in rats. cairo Dental J. 2010;26:29-37.

30. Bancroft J. D. and Stevens A. Theory and practice of histological techniques. $3^{\text {rd }}$ ed: Churchill Livingstone; 1990.

31. Mitsuta T., Horiuchi H. and Shinoda H. Effects of topical administration of clodronate on alveolar bone resorption in rats with experimental periodontitis. J Periodontol. 2002 May;73(5):479-86.

32. Aurore V., Caldana F., Blanchard M., Hess S. K., Lannes N., Mantel P.-Y., Filgueira L. and Walch M. Silvernanoparticles increase bactericidal activity and radical oxygen responses against bacterial pathogens in human osteoclasts. Nanomedicine: Nanotechnology, Biology and Medicine. 2018 2018/01/26:601-7.

33. Vimbela G. V., Ngo S. M., Fraze C., Yang L. and Stout D. A. Antibacterial properties and toxicity from metallic nanomaterials. Int J Nanomedicine. 2017;12:3941-65.

34. Rai M., Yadav A. and Gade A. Silver nanoparticles as a new generation of antimicrobials. Biotechnol Adv. 2009 Jan-Feb;27(1):76-83.

35. Sondi I. and Salopek-Sondi B. Silver nanoparticles as antimicrobial agent: A case study on e. Coli as a model for gram-negative bacteria. J Colloid Interface Sci. 2004 Jul $1 ; 275(1): 177-82$.

36. Liau S. Y., Read D. C., Pugh W. J., Furr J. R. and Russell A. D. Interaction of silver nitrate with readily identifiable groups: Relationship to the antibacterial action of silver ions. Lett Appl Microbiol. 1997 Oct;25(4):279-83.

37. Kim J. S., Kuk E., Yu K. N., Kim J. H., Park S. J., Lee H. J., Kim S. H., Park Y. K., Park Y. H., Hwang C. Y., Kim Y. K., Lee Y. S., Jeong D. H. and Cho M. H. Antimicrobial effects of silver nanoparticles. Nanomedicine. 2007 Mar;3(1):95101.

38. Bhol K. C. and Schechter P. J. Topical nanocrystalline silver cream suppresses inflammatory cytokines and induces apoptosis of inflammatory cells in a murine model of allergic contact dermatitis. Br J Dermatol. 2005 Jun;152(6):1235-42.

39. Bhol K. C. and Schechter P. J. Effects of nanocrystalline silver (npi 32101) in a rat model of ulcerative colitis. Dig Dis Sci. 2007 Oct;52(10):2732-42.

40. Golub L. M., Lee H. M., Stoner J. A., Sorsa T., Reinhardt R. A., Wolff M. S., Ryan M. E., Nummikoski P. V. and Payne J. B. Subantimicrobial-dose doxycycline modulates gingival crevicular fluid biomarkers of periodontitis in postmenopausal osteopenic women. J Periodontol. 2008 Aug;79(8):1409-18.

41. Kuula H., Salo T., Pirila E., Tuomainen A. M., Jauhiainen M., Uitto V. J., Tjaderhane L., Pussinen P. J. and Sorsa T. Local and systemic responses in matrix metalloproteinase 8-deficient mice during porphyromonas gingivalis-induced periodontitis. Infect Immun. 2009 Feb;77(2):850-9.

42. Hernandez M., Gamonal J., Salo T., Tervahartiala T., Hukkanen M., Tjaderhane L. and Sorsa T. Reduced expression of lipopolysaccharide-induced cxc chemokine in porphyromonas gingivalis-induced experimental periodontitis in matrix metalloproteinase- 8 null mice. $\mathrm{J}$ Periodontal Res. 2011 Feb;46(1):58-66.

43. Kurgan S., Fentoglu O., Onder C., Serdar M., Eser F., Tatakis D. N. and Gunhan M. The effects of periodontal therapy on gingival crevicular fluid matrix metalloproteinase-8, interleukin-6 and prostaglandin e2 levels in patients with rheumatoid arthritis. J Periodontal Res. 2016 Oct;51(5):586-95.

44. Gul S. S., Douglas C. W., Griffiths G. S. and Rawlinson A. A pilot study of active enzyme levels in gingival crevicular fluid of patients with chronic periodontal disease. J Clin Periodontol. 2016 Aug;43(8):629-36.

45. Goncalves P. F., Huang H., McAninley S., Alfant B., Harrison P., Aukhil I., Walker C. and Shaddox L. M. Periodontal treatment reduces matrix metalloproteinase 
levels in localized aggressive periodontitis. J Periodontol. 2013 Dec;84(12):1801-8.

46. Syndergaard B., Al-Sabbagh M., Kryscio R. J., Xi J., Ding X., Ebersole J. L. and Miller C. S. Salivary biomarkers associated with gingivitis and response to therapy. J
Periodontol. 2014 Aug;85(8):e295-303.

47. Mirrielees J., Crofford L. J., Lin Y., Kryscio R. J., Dawson D. R., 3rd, Ebersole J. L. and Miller C. S. Rheumatoid arthritis and salivary biomarkers of periodontal disease. J Clin Periodontol. 2010 Dec;37(12):1068-74. 